\title{
Wear behavior of engine components affected by soot
}

Jens Jörns, Co-Authors: Dr. Andreas Jäger, Wolfgang Optatzy, Dr. Bernhard Kehrwald, all IAVF Antriebstechnik GmbH

Zum Zeitpunkt der Drucklegung lagen diese Unterlagen noch nicht vor. Wir bitten um Verständnis. 